\title{
Farklı Katı İçeriklerindeki Maden Artığı Macun Malzemenin Reolojik Davranışlarının İncelenmesi
}

\author{
Deniz Adıgüzel ${ }^{1^{*}}$ \\ $1^{*}$ Istanbul Üniversitesi-Cerrahpaşa, Mühendislik Fakültesi, Maden Mühendisliği Bölümü, İstanbul. \\ e-posta: deniza@istanbul.edu.tr ORCID ID: http://orcid.org/0000-0002-1611-1296
}

Öz

Anahtar kelimeler

Macun Malzeme;

Proses Artığı; Reolojik Özellikler; Maksimum Paketleme Yoğunluğu.

\begin{abstract}
Günümüzde madencilik sektörünün gelişimiyle beraber hammadde ihtiyacı da her geçen gün artmaktadır. İlerleyen teknolojinin getirdiği olanaklar sayesinde daha düşük tenörlü cevherler de ekonomik olarak değerlendirilmekte ve hammadde üretimi artmaktadır. Buna bağlı olarak cevher hazırlama ve zenginleştirme tesislerinde açığa çıkan artık malzeme oranı giderek artmakta ve bu durum çevresel açıdan büyük riskler oluşturmaktadır. Bu artıkların çevresel açıdan risk yaratmayacak bir şekilde depolanması madencilik sektörü açısından giderek büyüyen bir problem olmaktadır. Artık barajları gibi klasik depolama yöntemleri işletmelerin bu ihtiyaçlarını yeterince karşılayamamaktadır. Son yıllarda macun teknolojisi kullanımı klasik depolama yöntemlerine alternatif olmakta ve işletmelerde artıkların depolanması amacıyla bu teknolojinin kullanımı giderek artmaktadır. Bu yöntemin çevresel ve ekonomiklik açısından büyük avantajları bulunmaktadır, ancak uygulamada klasik artık depolama yöntemlerine göre daha fazla teknik özelliğin belirlenmesi gerekmektedir. Bunlardan en önemlileri macun malzemenin pompalanabilirliğini belirleyen reolojik özellikleridir. Bu çalışmada bir bakır madeni proses artıkları ile oluşturulan macun malzemenin reolojik davranışları incelenmiştir. Buna göre farklı katı oranlarında hazırlanan macun malzemenin akma gerilmesi, viskozite ve malzemenin akış özellikleri hakkında önemli bir parametre olan maksimum paketleme yoğunluğu değerleri bu çalışma kapsamında belirlenmiştir. Sonuç olarak macun malzemenin pompalanabilirlik açısından kritik katı oranı $\% 45$ olarak, maksimum paketleme yoğunluğu değeri ise \%68 olarak belirlenmiştir. Böylece katı oranı değişiminin macun malzemenin reolojik özelliklerine olan etkisi ve pompalanabilirlik açısından uygun katı oranları ortaya konulmuştur.
\end{abstract}

\section{The Investigation of Rheological behaviours of Tailing Paste Material in Different Solid Content}

\begin{abstract}
Today, with the development of the mining sector, the need for raw materials is increasing day by day. This need made it possible to evaluate the lower grade ores economically provided by the advancing technology. Thus, the amount of tailing material released has increased gradually and this has created environmental risks. Tailings disposal is a growing problem for the mining industry in terms of environmental. Conventional disposal methods, such as tailing dams, cannot adequately solve these problems. In recent years, the use of paste technology has become an alternative to tailing dams and the use of this technology has been increasing in order to tailings disposal in mining. This method has great advantages in terms of environmental and economic efficiency, but in practice it is necessary to determine more technical properties than conventional methods. The most important of these properties are the rheological behaviours which determine the pumpability of the paste material. In this study, the rheological behavior of the paste material formed by a copper mine process tailing was investigated. The yield stress, viscosity and maximum packaging density which are an important parameter about flow properties values of the paste material with different solid ratios were determined. As a result, the critical solids ratio of the paste material is $45 \%$ and the maximum packing density value is $68 \%$. Thus, the effect of the change in the solids ratio on the rheological properties of the paste material and the suitable solid ratios in terms of pumpability were determined.
\end{abstract}




\section{Giriş}

Hızla gelişmekte olan madencilik sektörü, özellikle üretim sırasında ortaya çıkan maden artıkları nedeniyle, birçok çevresel sorunlar ile karşılaşmaktadır. $\mathrm{Bu}$ artıkların yerüstünde geleneksel yöntemler kullanılarak depolanması sırasında oluşan çevresel zararlar macun teknolojisi gibi yeni gelişen artık depolama yöntemleri ile önemli ölçüde azaltılabilmektedir. Genellikle yerüstü artık barajlarına boşaltılan maden artıklarının, son yıllarda önemi giderek artan macun teknolojisi ile güvenli bir şekilde depolanabilirliği mümkün olmaktadır (Simms et al. 2007, Henriquez and Simms 2009 Deschamps et al. 2011).

Macun, cevher hazırlama tesis artıklarının susuzlaştırıldıktan sonra, tercihen bağlayıcı malzeme ve su ilavesi ile karıştırılarak belli bir kıvam değerine getirilen artık malzeme olarak tanımlanmaktadır (Cincilla et al. 1997). Madencilik faaliyetlerinde macun artık malzemesi yerüstü (yerüstü macun depolama) ve yer altı (macun dolgu) olmak üzere iki şekilde depolanmaktadır. Karışımda kullanılan katı malzeme (ağırıkça \%65-85 oranında), cevher zenginleştirme tesisinden elde edilen artık malzemelerdir. Macun malzemenin depolanabilirliği mekanik, fiziksel, kıvam ve kimyasal özelliklerine bağlı olmaktadır. Bunlar içerisinden en önemlilerinden biri malzemenin pompalanabilirliğini belirleyen reolojik davranışlarıdır. Macun malzemenin uzak mesafelere pompalanabilmesi için $150-250 \mathrm{~mm}$ slamp değerinin sağlaması, bunun yanında uygun akma gerilmesi ve viskozite değerlerine sahip olması gerekmektedir. Reolojik açıdan bakıldığında macun malzeme; Newton dışı akışkan özellik gösteren karışımlar olmakta ve genellikle Bingham plastik akışları olarak sınıflandırılmaktadır. Macun malzemede, enerji, akış sırasında bazı faktörler nedeniyle kaybedilebilir. Bu durumda, kayma gerilmesi ve kayma hızı arasında sabit bir orana sahip olmaz ve viskozite kayma hızı ya da kayma zamanı ile değişir. Macun malzemenin reolojik davranışları için önceden geliştirilen model çabaları şu ana kadar nispeten başarısız olmuştur. Ayrıca pompalanabilirlikle ilgili tecrübeler macun malzeme akış teorilerinin iyi anlaşılmadığını göstermiştir (Cooke 2008, Theriault et al. 2003).

Macun malzemenin reolojik davranışı oldukça karmaşık olup, bu davranışı açıklayan tek bir parametre yoktur. Literatürde malzemenin reolojik davranışları ve bu davranışa etki eden parametreler konusunda birçok çalışma bulunmaktadır. Bu malzemenin reolojik davranışını etkileyen başlıca önemli faktörler; katı oranı, bağlayıcı tipi ve oranı, mineral ve kimyasal katkı maddeleri, tanelerin yüzey özellikleri ve yüzey alanı olarak sıralanabilir. Bu faktörlerden en önemlisi malzemenin katı oranıdır. Katı oranının artması akışı zorlaştırmakta ve dolayısıyla viskozite ve akma gerilmesi değerlerini artırmaktadır (Verkerk and Marcus 1998, Chen et al. 2016). Katı oranı mekanik özelikleri de etkilemektedir. Bu nedenle bu değerin belirlenmesi malzemenin stabilizasyonu açısından da çok önemli olmaktadır. Bu nedenlerle artık depolama yöntemi olarak macun teknolojisini kullanan işletmeler açısından malzemenin uygulanabilir katı oranının belirlenmesi ve kontrol edilmesi gerekmektedir. Özellikle çevresel açıdan risklerin fazla olduğu metalik cevher artıkları için yerüstü macun teknolojisinin kullanımı avantajlıdır. Ülkemiz madenciliği açısından bu depolama teknolojisi yeni bir konudur. Yeraltı macun depolama metodu ise ülkemizde birkaç madende kullanılmaktadır. Bu çalışma ile elde edilecek sonuçlar proses artığının oluştuğu her madencilik çalışmasında kullanılabilecektir.

Bu çalışmanın ana amacı reolojik açıdan uygun katı oranının belirlenebilmesi için izlenecek yöntemin ortaya konulmasıdır. Ayrıca bu çalışma ile, macun depolama uygulamalarında, katı oranındaki değişimler nedeniyle oluşan pompalanabilirlik problemlerinin önceden tespit edilmesi sağlanacaktır. Bu çalışma kapsamında katı oranının macun malzemenin reolojik davranışlarına olan etkisi belirlenmiş ve özellikle macun malzeme oluşturulması için kritik katı oranları ortaya konulmuştur. 


\section{Materyal ve Metot}

\subsection{Malzeme}

Çalışma kapsamında kullanılan malzeme Bakır madeni üretimi sonrasında ortaya çıkan proses artıklarından oluşmaktadır. Malzemenin fiziksel ve kimyasal özellikleri Çizelge $1^{\prime}$ de verilmektedir.

Çizelge 1. Artık malzemenin fiziksel ve kimyasal özellikleri (Başçetin vd. 2018)

\begin{tabular}{ll}
\hline Fiziksel özellikler & Değer \\
\hline Yoğunluk $\left(\mathrm{g} / \mathrm{cm}^{3}\right)$ & 3,61 \\
Ortalama tane boyutu $\left(\mathrm{d}_{50}\right)(\mu \mathrm{m})$ & 40 \\
Maksimum tane boyutu $\left(\mathrm{d}_{\text {max }}\right)(\mu \mathrm{m})$ & 630 \\
\hline Kimyasal Bileşimi & \\
\hline $\mathrm{Fe}_{2} \mathrm{O}_{3}(\%)$ & 54,3 \\
$\mathrm{SiO}_{2}(\%)$ & 12,3 \\
$\mathrm{Al}_{2} \mathrm{O}_{3}(\%)$ & 4,1 \\
$\mathrm{MgO}(\%)$ & 2,3 \\
$\mathrm{CaO}(\%)$ & 1,8 \\
\hline
\end{tabular}

\subsection{Metot}

Macun malzeme katı oranları belirlenirken literatürde yer alan pülpte katı oranları esas alınmıştır. Buna göre artık ve su (deiyonize) kullanılarak pülpte katı oranları \%65 - \%80 (ağırlıkça) aralığında olan malzemeler hazırlanmış ve bir laboratuvar tipi karıştırıcı ile 15 dk sabit devirde (500 rpm) karıştırılmıştır. Çalışma kapsamında maksimum paketleme yoğunluğu değerleri de belirleneceğinden, hesaplamalarda hacimsel katı oranı değerleri kullanılmıştır. Buna göre çalışmada oluşturulan 6 farklı macun karışımın ağırlıkça ve hacimsel katı oranı değerleri Çizelge 2'de verilmektedir.

Çizelge 2. Macun malzemelerin ağırlıkça ve hacimsel katı oranı değerleri

\begin{tabular}{ll}
\hline $\begin{array}{l}\text { Pülpte katı oranı (\%)(ağırlıkça) } \\
\left(\mathbf{m}_{\mathrm{a}} / \mathbf{m}_{\mathrm{s}}+\mathbf{m}_{\mathrm{a}}\right) * \mathbf{1 0 0}\end{array}$ & $\begin{array}{l}\text { Katı oranı (\%) (hacimsel) } \\
\left(\mathrm{V}_{\mathrm{a}} / \mathbf{V}_{\mathbf{s}}+\mathrm{V}_{\mathrm{a}}\right) * \mathbf{1 0 0}\end{array}$ \\
\hline 65 & 34 \\
67,5 & 36,5 \\
70 & 39,3 \\
72,5 & 42,2 \\
75 & 45,4 \\
77,5 & 48,8 \\
80 & 52,6 \\
\hline $\mathrm{m}_{\mathrm{a}}, \mathrm{V}_{\mathrm{a}}$ :Artık malzeme ağırlığı ve hacmi; & $\mathrm{m}_{\mathrm{s}}, \mathrm{V}_{\mathrm{s}}:$ Suyun ağırlığı ve hacmi
\end{tabular}

Çizelge 2'de verilen tüm bu karışımlar üzerinde reometre cihazı ile reoloji testleri yapılmıştır. Bütün testler $23^{\circ} \mathrm{C}^{\prime}$ de yapılmıştır. Bu kapsamda maksimum kayma hızı $200 \mathrm{~s}^{-1}$ olarak belirlenmiş ve özellikle yoğun sıvıların reolojik davranışlarının belirlenmesinde tercih edilen vane metodu kullanılarak ölçümler yapılmıştır. Ölçümler sırasında kullanılan vane spindle ucun çapı $20 \mathrm{~mm}$ boyu ise 40 $\mathrm{mm}$ 'dir. Ayrıca deneyler $60 \mathrm{~mm}$ çapında (uç ve kap çeperi arası mesafe en az çapın 2 katı olacak şekilde) bir kap içerisinde yapılmıştır. Reometre cihazı kullanılarak artan kayma hızlarında $\left(0-200 \mathrm{~s}^{-1}\right)$ oluşan tork miktarı ölçülmüş ve eşitlik $1^{\prime}$ de verilen denklem kullanılarak kayma gerilmeleri hesaplanmıştır (Nguyen and Boger 1983).

$\tau=\mathrm{T} \times \frac{2}{\pi \mathrm{D}^{3}} \times\left(\frac{\mathrm{H}}{\mathrm{D}}+\frac{1}{3}\right)^{-1}$

Burada;

$\tau=$ Kayma gerilmesi

T=Tork

$\mathrm{D}=$ Vane spindle uç çapı

$\mathrm{H}=$ Vane spindle uç uzunluğu

Macun karışımları genellikle Bingham plastik akışları olarak sınıflandırılır. Bingham tipi akışların reolojik denklemi eşitlik 2'de verilmiştir (Kwak et al. 2005).

$\tau=\sigma+\mu\left(\frac{d u}{d y}\right)$

Burada;

$\tau=$ Kayma gerilmesi $(\mathrm{Pa})$

$\sigma=$ Akma gerilmesi

$\mu=$ Plastik viskozite (Pa.s)

$\mathrm{du} / \mathrm{dy}=$ Kayma hızı $\left(\mathrm{s}^{-1}\right)$

Reoloji deneyleri sırasında eşitlik 2 kullanılarak malzemelerin akma gerilmesi ve viskozite değerleri belirlenmiştir. Ayrıca malzemenin maksimum paketleme yoğunluğu değeri de belirlenmiştir. Bu değer karışım içerisindeki uygulanabilecek maksimum katı içeriğini vermektedir. Her malzeme için değişen bu değerin aşılması durumunda malzemenin karışması ve pompalanabilmesi oldukça zor olmaktadır (Deng et al. 2018). Bu değer belirlenirken öncelikle farklı katı oranlarındaki malzemelerin aynı akma gerilmesindeki viskozite değerleri belirlenmiştir (eşitlik 3). Daha sonra eşitlik 4 ve grafik çizim kullanılarak katı oranının paketleme yoğunluğuna eşit olduğu değerler belirlenmiştir. Bu paketleme yoğunlukları içerisinde en yüksek olanı 
maksimum paketleme yoğunluğu değeri olarak alınmıştır (Treger et al. 2010).

$$
\mu=\tau / \mathrm{du} / \mathrm{dy}
$$

Burada;

$\mu=$ Plastik viskozite (Pa.s)

$\tau=$ Kayma gerilmesi $(\mathrm{Pa})$

$\mathrm{du} / \mathrm{dy}=$ Kayma hızı $\left(\mathrm{s}^{-1}\right)$ $\frac{\phi}{\phi_{m}}=\left(1-\sqrt{\frac{\mu_{0}}{\mu}}\right)$

Burada;

(3) $\phi=$ Katı Oranı

$\phi_{\mathrm{m}}=$ Paketleme yoğunluğu

$\mu=$ Macun malzemenin viskozitesi

$\mu_{0}=$ Suyun Viskozitesi

(23ㄷ'ㄹeki suyun viskozitesi: 0,00093 Pa.s)

\section{Bulgular ve Tartışma}

Toplam 6 farklı katı oranında oluşturulan macun malzeme üzerinde yapılan reoloji testleri sonucunda malzemelerin değişen kayma hızına bağlı kayma gerilmesi değerleri belirlenmiş ve bu ilişkiler Şekil 1 ve Şekil2 'de verilmiştir.

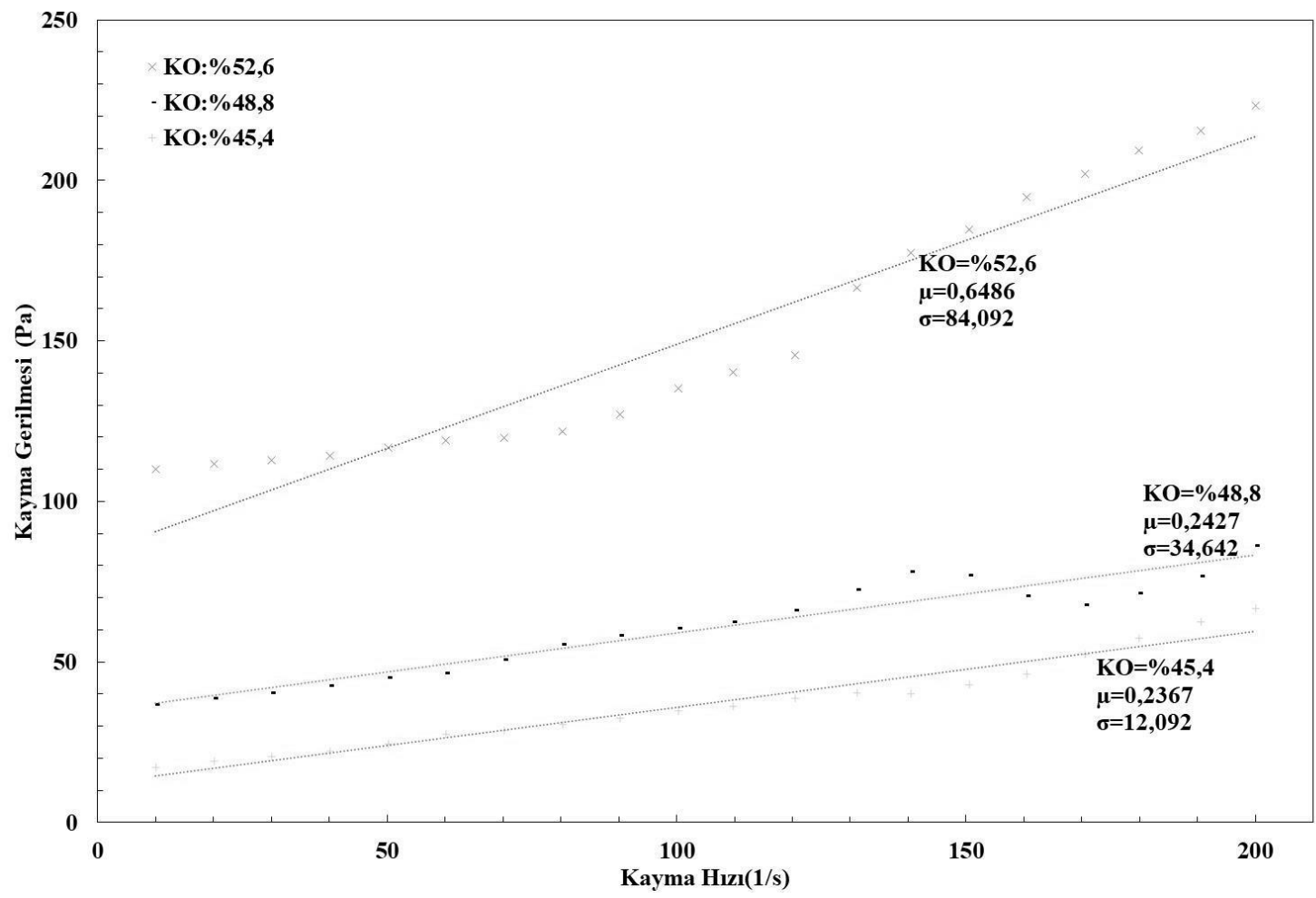

Şekil 1. \% 45,4'den büyük katı oranlarına sahip macun malzemenin kayma hızına bağlı kayma gerilmesi değişimi 


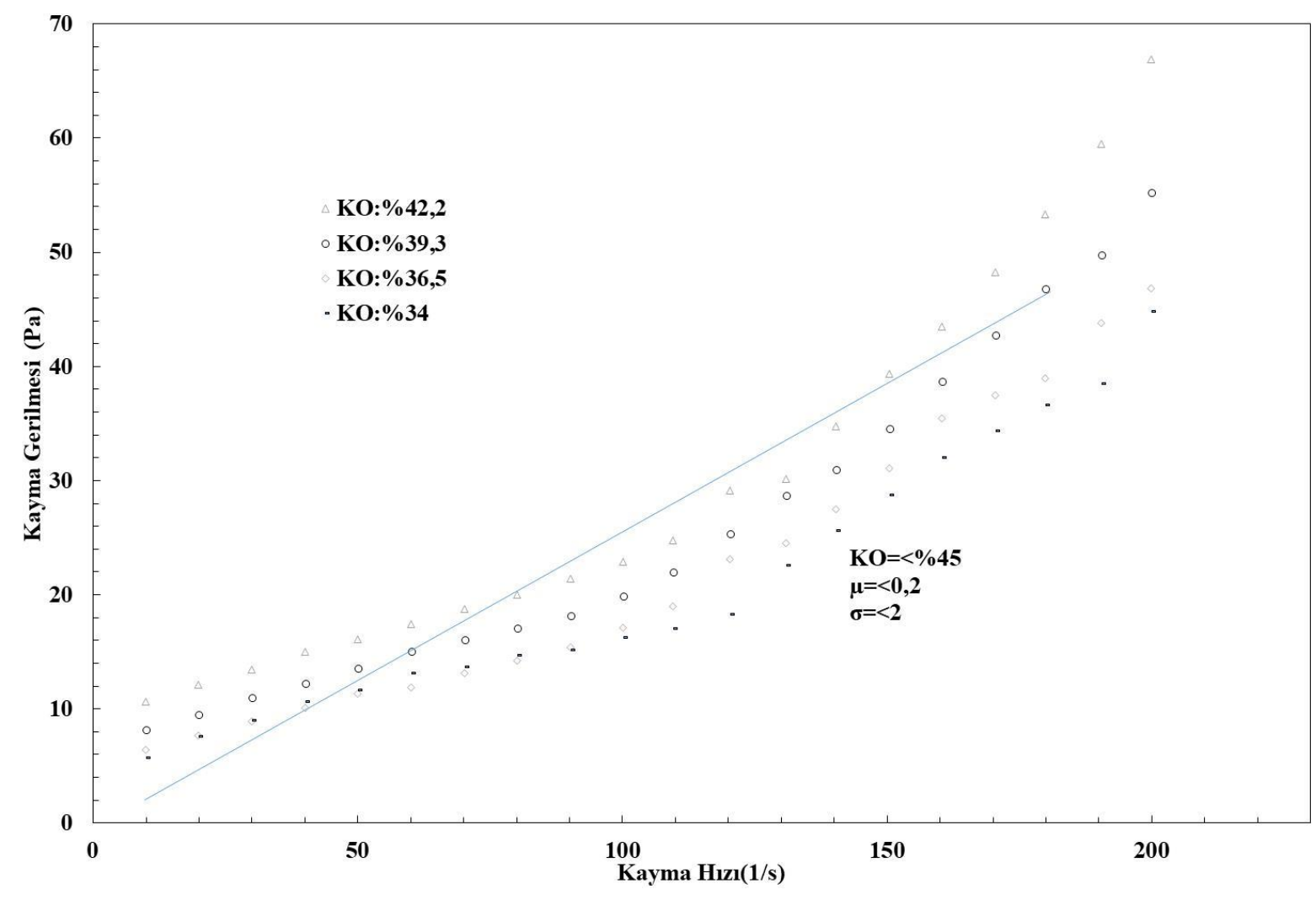

Şekil 2. \% 45,4'den küçük katı oranlarına sahip macun malzemenin kayma hızına bağlı kayma gerilmesi değişimi

Şekil 1 ve Şekil 2 'den de görüldüğü gibi \%45,4'den (Pülpte katı oranı \%75) büyük katı oranına sahip macun malzemeler diğer karışımlara göre reolojik açıdan farklı davranmaktadır. Bu değerden daha küçük katı oranına sahip macun malzemelerin viskozite ve akma gerilmesi değerleri birbirlerine yakın olmaktadır. Ayrıca bu malzemelerin akma değerlerinin çok düşük olması ( $<2 \mathrm{~Pa})$ nedeniyle malzemenin Newton akış sınıfına girdiğini ve malzemede macun kıvamının oluşmadığı söylenebilir. Bu sonuçlara göre bu malzeme için macun oluşturma katı oranı alt limitinin \%45,4 (Pülpte katı oranı \%75) olduğu söylenebilir. $\% 45,4$ 'den (Pülpte katı oranı \%75) büyük katı oranına sahip macun malzemelerin akma gerilmesi ve viskozite değerleri beklenildiği gibi katı oranına bağı olarak artmaktadır (Şekil 3).

Şekil 3'den de görüldüğü gibi macun malzeme oluşumu için kritik katı oranı değeri $\% 45,4$ 'dür. Akma gerilmesi değerleri \%45,4 katı oranı için $\sim 12 \mathrm{~Pa}, \% 48,8$ katı oranı için $~ 35 \mathrm{~Pa}$ ve $\% 52,6$ katı oranı için 84Pa olarak bulunmuştur. $100 \mathrm{~Pa}$ 'dan küçük akma gerilmesi değerine sahip macun malzemeler santrifüj tip pompa kullanılarak nakledilebilmektedir. $\mathrm{Bu}$ nedenle bu değerler macun malzeme açısından düşük olarak kabul edilebilir.

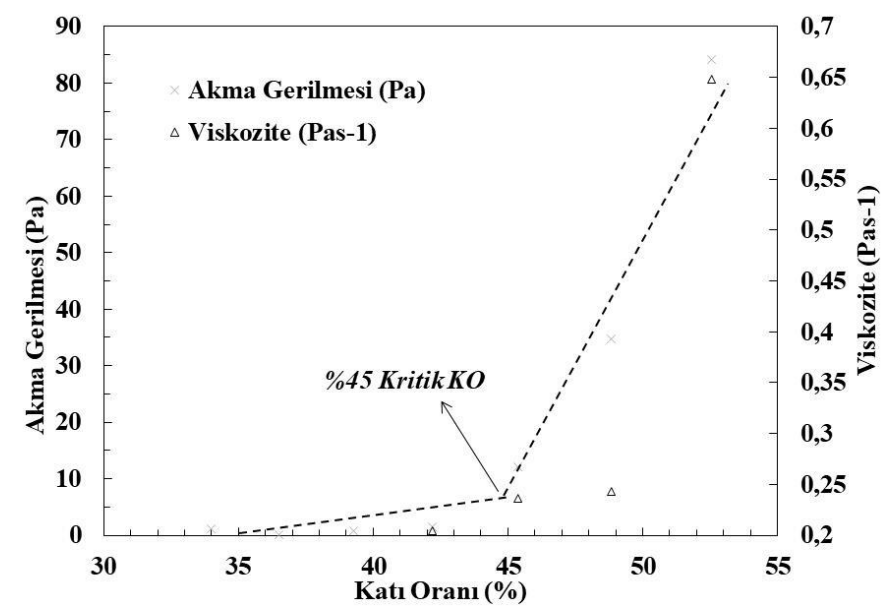

Şekil 3. Katı oranına bağlı olarak malzemenin akma gerilmesi ve viskozite değişimleri

Akma gerilmesi ve viskozite değerlerinin belirlenmesinden sonra macun malzemenin maksimum paketleme yoğunluğu değeri bulunmuştur. Öncelikle en büyük ve en küçük değerleri de kapsayacak 4 farklı kayma gerilmesinde 
(10 Pa,20 Pa,50 Pa ve $65 \mathrm{~Pa}$ ) viskozite değerleri hesaplanmıştır. Daha sonra eşitlik 4 ve grafik çizim kullanılarak katı oranının paketleme yoğunluğuna eşit olduğu değerler belirlenmiştir. Örnek olması açısından $50 \mathrm{~Pa}$ için Paketleme yoğunluğu değerinin hesaplanması Şekil 4 ve 5'de gösterilmektedir.

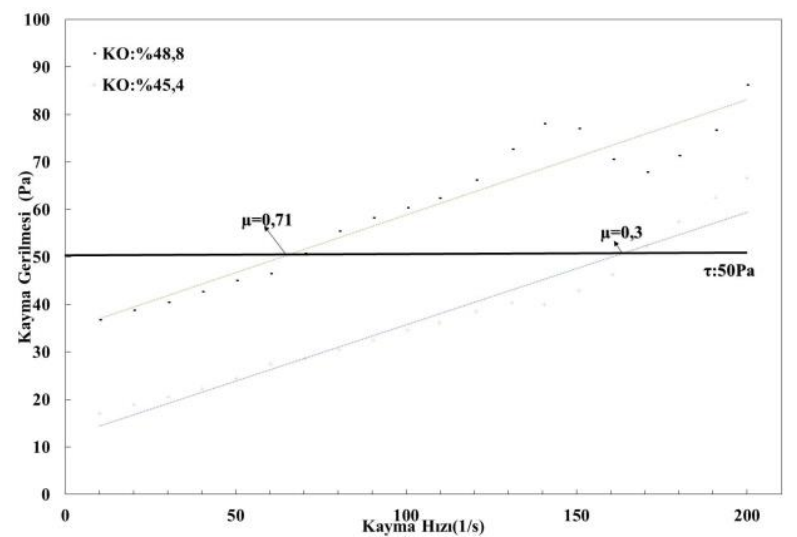

Şekil 4. $50 \mathrm{~Pa}$ kayma gerilmesi değeri için farklı katı oranlarındaki viskozite değişimleri

Şekil 4'de görüldüğü gibi $50 \mathrm{~Pa}$ kayma gerilmesi değerinde \%48,8 katı oranı için viskozite değeri 0,71 ve $\% 45,4$ katı oranı değeri için ise viskozite değeri 0,3 olarak hesaplanmıştır.

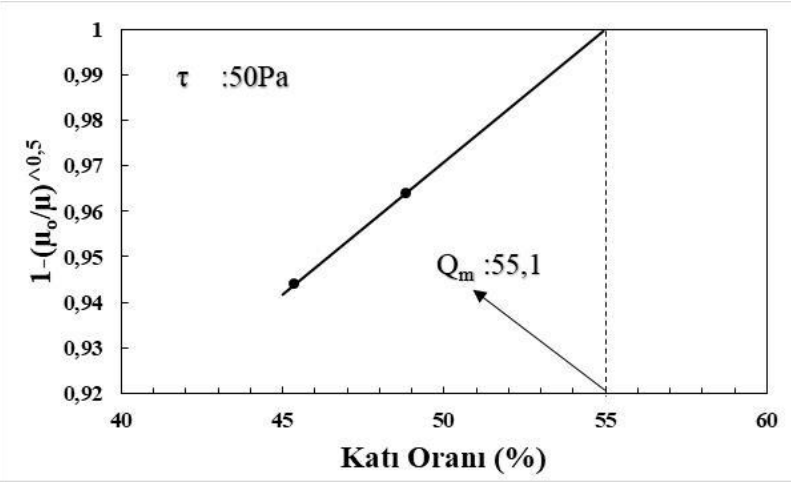

Şekil 5. 50 Pa kayma gerilmesi değeri için paketleme yoğunluğu değeri

$50 \mathrm{~Pa}$ için bulunan viskozite değerlerinden $\frac{\phi}{\phi_{m}}$ oranları hesaplanmış ve Şekil 5' de de görüldüğü gibi $\% 48,8$ katı oranı için bu değer 0,964 ve \%45,4 katı oranı için 0,944 olarak bulunmuştur. Bu değerlerin birleştirilmesiyle çizilen doğrunun 1 ile kesiştiği değerdeki katı oranı aynı zamanda paketleme yoğunluğu değeridir. Buna göre $50 \mathrm{~Pa}$ için paketleme yoğunluğu değeri $\% 55,1$ olarak hesaplanmıştır. Bu değer 4 farklı (10 Pa,20 Pa,50 Pa ve $65 \mathrm{~Pa}$ ) kayma gerilmesi değeri için hesaplanmış ve sonuçları Şekil 6 'da verilmiştir.

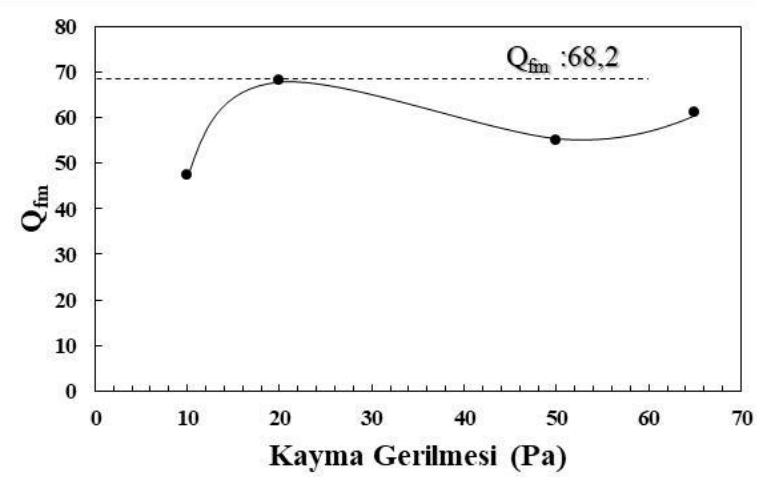

Şekil 6. 4 farklı kayma gerilmesinde paketleme yoğunluğu değerleri

Şekil 6'dan da görüldüğü gibi en yüksek paketleme yoğunluğu değeri dolayısıyla maksimum paketleme yoğunluğu değeri $\% 68,2^{\prime}$ dir. Bu değer aynı zamanda macun oluşumu açısından üst limit olarak kabul edilebilir. Bu değerden daha fazla katı oranlarında oluşturulacak macun malzemeler için pompalama ve karıştırma işlemeleri oldukça zor olacaktır. Demir artıkları kullanılarak oluşturulan macun malzemeler ile yapılan başka bir çalışmada maksimum paketleme yoğunluğu değeri $\% 56,91$ olarak bulunmuştur (Deng et al. 2018). Bu değer malzemenin birçok fiziksel ve kimyasal özelliğine bağlı olmakta ve her malzeme için değişkenlik göstermektedir. $\mathrm{Bu}$ nedenle macun malzeme tasarımlarında her malzeme için reolojik çalışmaların detaylı bir şekilde yapılması ve bu kritik katı oranlarının ortaya konulması gerekmektedir.

\section{Sonuç}

Madencilik sektörü açısından çevresel riskler oldukça önemli bir konudur. Özellikle artık depolama sırasında yaşanılan sorunlar çevresel açıdan büyük felaketlerle sonuçlanabilmektedir. Bu nedenle artık depolama sorununun çevreye zarar vermeyecek şekilde çözülmesi gerekmektedir. Macun teknolojisinin hem ekonomik hem de çevresel avantajları nedeniyle artık depolama alanında kullanımı giderek artmıştır. Bu yöntemin gelecekte artık barajlarının yerini alabileceği öngörülmektedir. $\mathrm{Bu}$ çalışmada macun teknolojisinin kullanımı açısından önemli bir 
parametre olan malzeme pompalanabilirliği incelenmiştir. Macun malzeme özellikleri açısından pompalanabilir olması gerekmektedir. $\mathrm{Bu}$ teknolojide malzemenin pompa ile nakliyesi, işletme ve yatırım maliyetinin büyük bir kısmını oluşturmakta ve uygulanabilirliğini büyük ölçüde belirlemektedir. Stabilite ile beraber önemli bir özellik olan pompalanabilirlik, malzemenin reolojik özellikleri ile belirlenmektedir. Bu çalışmada da bakır madeni proses artıkları kullanılark oluşturulan macun malzemelerin reolojik davranışları malzemenin katı oranına göre incelenmiş ve uygulanabilir katı oranları reolojik açıdan ortaya konulmuştur. Sonuçlara göre bu malzeme için macun oluşturma katı oranı alt limitinin $\% 45,4$ (Pülpte katı oranı \%75) olduğu söylenebilir. $\% 45,4$ 'den (Pülpte katı oranı \%75) büyük katı oranına sahip macun malzemelerin akma gerilmesi ve viskozite değerleri beklenildiği gibi katı oranına bağlı olarak artmaktadır. Buna göre kritik macun katı oranı \%45 olarak bulunmuş. Ayrıca maksimum paketleme oranı değeri de bu malzeme için \%68 olarak bulunmuştur. Bu değerler pompalanabilirlik açısından macun malzemenin limit değerleridir. Ayrıca farklı malzemelerle yapılacak macun tasarımlarında bu çalışmada uygulanan metodolojinin kullanılabileceği düşünülmektedir:

\section{Kaynaklar}

Başçetin, A., Eker, H., Tüylü, S. ve Adıgüzel, D., 2018. Bir Başçetin, A., Eker, H., Tüylü, S. ve Adıgüzel, D., 2018. Bir bakır madeni artıklarının dayanım özelliklerinin belirlenmesi. 12. Bölgesel Kaya Mekaniği Sempozyumu, 162-167.

Chen, Q., Zhang, Q., Wang, X., Xiao, C. and Hu, Q., 2016. $A$ hydraulic gradient model of paste-like crude tailings backfill slurry transported by a pipeline system. Enviromental Earth Science.

Cincilla, W.A., Landriault, D.A. and Verburg, R., 1997. Application of paste technology to surface disposal of mineral wastes. Proceedings of the Fourth International Conference on Tailings and Mine Waste, 343-356

Cooke, R., 2008. Pipeline design for paste and thickened tailings systems. Tailings and mine waste'08, 95-100.

Deng, X.J., Klein, B., Hallbom, D.J., Wit, B. and Zhang, J.X., 2018. Influence of particle size on the basic and time- dependent rheological behaviors of cemented paste backfill. Journal of Materials Engineering and Performance, 27, 3478-3487.

Deschamps, T., Benzaazoua, M., Bussière, B. And Aubertin, M., 2011. Laboratory study of surface paste disposal for sulfidic tailings: Physical model testing. Minerals Engineering, 24, 794-806.

Henriquez, J., Simms, P., 2009. Dynamic imaging and modeling of multilayer deposition of gold paste tailings. Minerals Engineering, 22, 128-139.

Kwak, M., James, D. F. and Klein, K. A., 2005. Flow behaviour of tailings paste for surface disposal. Int. J. Mineral Processing, 77, 139-153.

Nguyen, Q.D. and Boger, D.V., 1983. Yield stress measurement for concentrated suspensions. Journal of Rheology, 27, 321-349.

Simms, P., Grabinsky M. and Zhan, G., 2007. Modeling evaporation of paste tailings from the Bulyanhulu mine. Canadian Geotechnical Journal, 44(12), $1417-$ 1432

Theriault, J., Frostiak, J. and Welch, D., 2003. Surface disposal of paste tailings at the Bulyanhulu gold mine. Tanzania. Proceedings of Sudbury, Mining and the Environment, 265-269.

Tregger, N.A.,.Pakula, M.E. and Shah, S.P., 2010. Influence of clays on the rheology of cement pastes. Cement and Concrete Research, 40, 384-391

Verkerk, C.G. and Marcus, R.D., 1988. Backfill in South African Mines. South African Institute of Mining and Metallurgy, 221-233. 